University of Nebraska - Lincoln

DigitalCommons@University of Nebraska - Lincoln

Faculty Publications: Department of Entomology

Entomology, Department of

2020

Posters as an effective assessment tool for a capstone course

David Gosselin

University of Nebraska at Lincoln, dgosselin2@unl.edu

Doug Golick

University of Nebraska-Lincoln, dgolick2@unl.edu

Follow this and additional works at: https://digitalcommons.unl.edu/entomologyfacpub

Part of the Entomology Commons, and the Science and Mathematics Education Commons

Gosselin, David and Golick, Doug, "Posters as an effective assessment tool for a capstone course" (2020). Faculty Publications: Department of Entomology. 850.

https://digitalcommons.unl.edu/entomologyfacpub/850

This Article is brought to you for free and open access by the Entomology, Department of at DigitalCommons@University of Nebraska - Lincoln. It has been accepted for inclusion in Faculty Publications: Department of Entomology by an authorized administrator of DigitalCommons@University of Nebraska - Lincoln. 


\title{
Posters as an effective assessment tool for a capstone course
}

\author{
David C. Gosselin ${ }^{1}$ • Doug Golick ${ }^{2}$
}

(C) AESS 2020

\begin{abstract}
A rubric was developed to assess student posters as a mechanism to evaluate learning outcomes for a senior capstone course. The analytic rubric allows for the efficient and systematic collection of data from posters by students who worked across a variety of disciplines including the physical, biological, Earth sciences, social science, and the humanities. The rubric effectively addressed a fundamental assumption and requirement put forth during rubric development, that is, it needs to be relatively easy to use without training while at the same time producing consistent results across evaluators. The overall Chronbach's alpha of 0.80 across semesters indicates acceptable inter-rater reliability. Data generated by assessment of 106 interdisciplinary posters indicates a general, yet not statistically significant, improvement, in total scores from the spring 2014 to spring 2018, documents student proficiency, and captures the variability in the quality of the various projects. The rubric was primarily developed as a tool to inform formative assessment, but it is also a teaching tool. Its use in providing feedback and as reflection tool enhances the learning experience for students and increases the impact of the senior thesis process on their professional development. The use of a student feedback questionnaire has informed reflective instructional practice. This resulted in an increased emphasis within the capstone course on the inclusion of reference citations, use of informal writing activities, and frequency of meetings with faculty mentors. The results from our approach should be encouraging to other interdisciplinary environmental studies and science programs that seek to efficiently and effectively impact student learning outcomes and evaluate the impact of course changes over several semesters.
\end{abstract}

Keywords Assessment $\cdot$ Formative assessment $\cdot$ Higher education $\cdot$ Rubric development $\cdot$ Capstone course

\section{Introduction}

Over the past 30 years, assessment has become an increasingly important part of the higher education landscape (Hawthorne et al. 2018; Kuh et al. 2015). Assessment activity is often conducted in response to the demands and expectations of stakeholders including policymakers, accreditors, and donors, among others. The foundation for assessment lies in fundamental questions that drive any research process whether it be for academic purposes, our personal lives, or an employer. That is, how can we improve what we know, what we

David C. Gosselin dgosselin2@unl.edu

1 Environmental Studies Program \& School of Natural Resources, University of Nebraska-Lincoln, 150 Hardin Hall 3310 Holdrege, Lincoln, NE 68583-0941, USA

2 Department of Entomology Entomology Hall, University of Nebraska-Lincoln, Lincoln, NE 68583-0816, USA do, and how we do it? Educational assessment is about the systematic collection of data and use of information about educational programs to improve student learning and development (Palomba and Banta 1999). It also enables educators to discern the extent which they achieve their personal objectives and/or those of their institution (Skocpol 2009).

The institutional commitment to address instructional impact and improvement at the University of Nebraska-Lincoln (UNL) has been formalized into a three-stage process of outcome assessment. This process occurs at the institutional, college, and program level. It includes defining desired student learning outcomes, identifying the best measures for determining whether these outcomes have been realized, and using results to confirm and/or improve instructional and curricular practice. At the institutional level, the Achievement-Centered Education (ACE), UNL initiated a general education program (https://ace.unl.edu/) during the 2009-2010 academic year. It was built on student learning outcomes that were developed to answer the fundamental question "What should all undergraduate students - irrespective of their majors and career aspirations - know or be able to do upon graduation?" This 
program consists of ten learning outcomes (ACE 1-10) designed to provide all students with the opportunity to develop a broad foundation of skills, build knowledge, exercise social responsibility, and integrate what they learn into their lives. The ACE 10 course, generally, serves as a capstone-type experience in which students have the opportunity to integrate their abilities and capabilities to adapt to new settings, questions, and responsibilities.

This paper is a descriptive study that aims to help determine the current state of student's abilities to meet the requirements of a capstone course experience during which the student generates a creative or scholarly product. This product serves to demonstrate broad knowledge, appropriate technical proficiency, and the ability to collect data and information along with the ability to synthesize, interpret, and present. The assessment of the products is the foundation for reflective practice and the continual improvement of teaching practice within the program. This paper has three specific objectives. The first focuses on the development and evaluation of a poster assessment rubric used in a senior capstone by the UNL Environmental Studies Program to assess capstone course learning outcomes. The second objective is to apply the rubric as a formative assessment to assist in the improvement in educational practice. The specific research question related to this objective is to what extent can senior thesis posters inform the Environmental Studies program about the extent to which students are achieving the ACE 10 capstone course outcome, that is "each student will generate a creative or scholarly product that requires broad knowledge, appropriate technical proficiency, information collection, synthesis, interpretation, presentation, and reflection." The third objective is to evaluate student perceptions about the senior capstone course using a senior questionnaire to inform the capstone course process.

\section{Institutional setting and course sequence overview}

The University of Nebraska, Lincoln is a Land Grant Institution and Carnegie-classified research university with very high research activity and high undergraduate enrollment. The College of Arts and Sciences (CAS) and the College of Agricultural Sciences and Natural Resources (CASNR) jointly own and operate the undergraduate Environmental Studies program. A part-time (0.2 FTE) program director is the only faculty-associated appointment assigned to the unit. Two part-time academic advisors, one from each college support the director. This program has no faculty FTE assigned to it. The program currently has over 160 majors, double majors, and minors. These limited resources lead to the practical question, what is feasible in terms of data collection given the other obligations and resource limitations of staff time and the lack direct access to faculty?

To graduate from the Environmental Studies program, students take 120 student credit hours (SCH) that include 13 $\mathrm{SCH}$ in six core courses in Environmental Studies (ENVR). This paper focuses on the two-semester senior thesis capstone sequence of ENVR 499a and ENVR 499b. Together, these courses meet ACE 10 requirements. In addition to meeting these curriculum requirements, this course sequence helps students meet two program learning outcomes and 12 specific course level learning outcomes (Table 1). Students typically complete the two courses over two consecutive semestersfall/spring or spring/fall. To generate a creative or scholarly product, referred to as a senior thesis, the student needs to engage actively in the five Ps of the process (Fig. 1). Engaging in the five Ps is a significant endeavor throughout which the student uses critical thinking and problem-solving skills, employs writing and presentation skills, and practices professional skills.

Each project provides an authentic research/creative experience that requires the student to develop and be responsible for the investigation/project. It is about a student-driven process of an investigation/creative endeavor, and not necessarily about doing novel, cutting-edge research or creative activity for publication. The ENVR 499 course sequence includes the four key characteristics of what counts as an undergraduate "dissertation" in the English system. That is, the student is responsible for defining the scope/focus of the work through the development of their research question and project foci based on their interest and passion for the topic. An individual student or pair of students under the guidance of two mentors, a thesis advisor, and a reader carries out the work. Students solicit advice and input as they develop their ideas, research questions, methodologies, and required products (Fig. 1). Research involves the analysis of primary or secondary data, and students are engaged with their project activities for an extensive period (Todd et al. 2004). This approach contrasts to the design of some senior projects where a student is assigned to a project on which to work (Weaver et al. 2016). UNL students organize, plan, and use appropriate technical knowledge, field, laboratory, geospatial, and/or social science research methodologies along with reasoning to form conclusions.

The foci of the research/creative projects range across an interdisciplinary spectrum of topics. Examples of topics from the spring 2018 semester include analysis of the social and political barriers to wind energy development; nutrient removal from a lake using a floating wetland design; modeling soil carbon sequestration; linking childhood experiences in nature to adult environmental attitudes, beliefs, and behaviors; college student perceptions of environmental justice; and adoption of soil moisture sensors by future farmers in Nebraska. 
Table 1 Program learning outcomes (LO) and specific course learning outcomes for ENVR 499a and 499b sequence

PLO 1. Organize, plan, and satisfactorily complete a scholarly creative or research product that uses appropriate technical knowledge, field, laboratory, geospatial, and/or social science research methodologies. (Related Course Learning Outcomes - 1,2,3,4,5)

PLO 2. Communicate effectively to a range of audiences through the preparation of written documents along with oral and visual presentations that are consistent with professional standards. (Related Course Learning Outcomes - 6,7)

\section{ENVR 499a. Course Learning Outcomes}

By the end of ENVR 499a, students will:

L.O. 1. Identify a scholarly, creative and/or research topic of interest.

L.O. 2. Identify a thesis advisor and thesis reader.

L.O. 3. Compose an actionable research question/hypothesis/objective for the project.

L.O. 4. Formulate an action plan to complete the project.

L.O. 5. Assemble a literature review that adequately describes and supports the relevance and action plan for the project.

L.O. 6. Prepare a properly formatted and written thesis/project proposal consistent with professional standards.

L.O. 7. Effectively present an oral presentation of your scholarly, creative, and/or research

\section{By the end of 499b, students will:}

\section{ENVR 499b. Course Learning Outcomes}

L.O. 1. Complete a scholarly, creative and/or research topic of interest.

L.O. 2. Successfully complete a poster presentation about your project that passes the poster rubric.

L.O. 3. Effectively present an oral presentation of your scholarly, creative and/or research

L.O. 4. Prepare a properly formatted and written thesis/project paper consistent with professional standards of the discipline within which you are working with your thesis adviser and reader.

L.O. 5. Complete final program assessments

ENVR 499a, a one-credit course, prepares the student to complete the senior research, creative, or scholarly project. This class is an abbreviated version of a research methods class. It consists of directed reading assignments, question

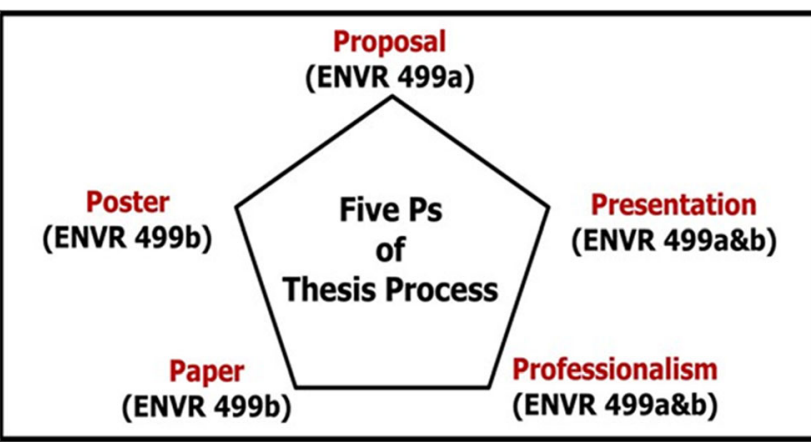

Fig. 1 Five Ps of thesis process development, overview of qualitative, quantitative, and mixed methods, peer-reviewed writing assignments, and directed outside research. The products of ENVR 499a include a written proposal and oral presentation that summarizes the importance of their project and methods they will use to achieve their stated objectives or address their research questions. ENVR 499b is a two SCH course during which the student completes their senior thesis/project. The class meets four to six times a semester and uses peer-review sessions to assist the students in the development of their final written thesis, oral presentation, and poster. At the end of each semester, posters from all projects are featured at the Environmental Studies Showcase. All posters are assessed using the common rubric as subsequently described. To gather input about the senior thesis process, we solicit reflective feedback from graduating seniors using a senior questionnaire. 


\section{Methodology}

\section{Rubric development}

As the result of a curriculum update process from 2008 to 2010 (Gosselin et al. 2013), the senior thesis requirement, which was the foundation of the program since its inception in the early 1990s, became more formalized. Since the 2010 2011 academic year, Environmental Studies students have been required to present a poster of their final thesis/creative project. The timing of these changes corresponded with the implementation of ACE assessment requirements. This requirement resulted in the creation of the 1 st version of a rubric (version 1.0) to evaluate learning outcomes using the final poster presentation.

Using a deliberate and conscientious reflective approach to better understand and improve the rubric as advocated by Harvey et al. (2016), the first author participated in the ACE 10 Quality Initiative Project (https://ace.unl.edu/assessment/ ACE10project) during the 2012-2013 academic year. This program helped UNL faculty:

- Explore methods and tools for assessing work produced in ACE 10 courses

- Develop a collegial community who can share ideas about ACE 10 curriculum and assessment

- Sponsor conversation on connecting ACE 10 assessment to department's major curriculum

- Develop a useful process for creating your unit's ACE 10 assessment report

It should be noted that UNL does not provide specific student performance expectations for ACE courses. Each major/ program develops their own expectations. The Environmental Studies program used data derived from the ACE 10 materials as a formative assessment to improve the academic program and provide a baseline that could be used in the future to establish student performance outcomes.

A self-examination of the rubric clearly indicated that version 1.0 did not align well with the ACE 10 outcomes, nor did it capture the variability in the quality of the work presented on the posters. The 1.0 rubric also required that raters talk to the student presenter. This created several challenges. One of these was that the assessment became more about evaluating the student oral presentation skills rather than performance on the research product and processes as presented in the poster as an artifact. Another challenge was the limited amount of faculty time to rate a large number of posters. This is further compounded by the fact that some faculty had last-minute scheduling conflicts arise, and to accommodate this, these faculty were allowed to evaluate digital versions of their assigned posters. These challenges and limitations created considerable problems in logistics and in score variation due to the emphasis on oral presentation skills. This minimized rubric 1.0's utility as a framework for assessing student work and the extent to which the program was helping students with their ability to organize, plan, research, and complete a scholarly creative project.

Reflecting on these issues and utilizing feedback from faculty raters, the rubric was modified with an emphasis on standardizing the poster format, allowing assessment of the varied study areas of environmental sciences, scoring that captured the variation in the quality of the various components of the poster, and the elimination of scoring based on student-rater interaction during the poster session. In addition, we sought to address other basic assumptions including:

- A respect for the limited resources (time, people) for assessment

- Flexibility in process to meet a growing number of students

- Respect for reviewers' time-less than $1 \mathrm{~h}$ of review required

- Evaluation of ACE 10 components

- Relatively easy to use rubric that requires no training

An important outcome of the ACE 10 Quality Initiative Project was a peer review of the ENVR poster rubric by faculty colleagues from across UNL. This helped align the evaluative rubric components with the specifically articulated ACE 10 requirements. The result was a refined rubric (version 2.0) intended to evaluate the poster product without the assessor having to meet with the student or know anything about the specific content area of study.

The ACE 10 learning outcomes provided the criteria for the task analysis for the required knowledge and skills. Each subsection had 2 to 5 items (Table 2). The items were developed with the intention of capturing a progression in cognitive complexity similar to Bloom's Taxonomy from basic knowledge to analysis. For individual items, the scale asks the rater to determine the extent to which they see evidence for the criteria: evidence present, 2 points; no evidence, 0 points; and maybe present, giving them the benefit of the doubt so to speak, 1 point. There are eight subsections to the rubric that have maximum scores that vary from 4 to 10 points. Seven of these subsections assess project-related processes and content. The eighth subsection assesses the design and presentation characteristics of the poster. The maximum rubric score is 56 . The peer review of the rubric support the validity of the rubric content in that the content is aligned with and captures the essential elements of the specifically articulated requirements of the ACE 10 learning outcome. The criteria were distinct and the language was relatively unambiguous.

Consistent with the recommendations from Moskal (2003) and references therein on the use of rubrics for assessment, the 
Table 2 Poster assessment rubric for environmental studies research and creative experiences

\section{NRES 499B - Poster Assessment Rubric Form}

Name of Evaluator:

Poster Presenter and Title:

Step 1. Examine all the posters to give you context for your reviaw of the individual poster.

step 2. Examine your assigned poster. Use the rubric. For each assessment area, please answer the questions.

step 3. Turn in your evaluation form in at the Environmental studies table with your scores totaled.

\begin{tabular}{|c|c|c|c|c|}
\hline \multirow{2}{*}{$\begin{array}{l}\text { Instructions: For each assessment question, please check the relevant box. } \\
\text { Scoring is as follows: } 0 \text { = No evidence he/she addressed question; } 1 \text { = Some evidence, not } \\
\text { as cleor os it could be; } 2 \text { = Evidence ond linksges ore cleorly presented. } \\
\text { Please provide commenta to help the presenter improve. }\end{array}$} & \multicolumn{3}{|c|}{ Score } & \multirow[t]{2}{*}{ Comments } \\
\hline & 0 & 1 & 2 & \\
\hline \multicolumn{5}{|l|}{$\begin{array}{l}\text { Introduction and Connections to Brosd Knowledge: } \\
\text {-Did atudent place the research/project in the context of previous work in the field? } \\
\text { - Did the student explain the aignificance and importance of the topic/project? } \\
\text {-Did the student link their explanations to references from the literature? }\end{array}$} \\
\hline \multicolumn{5}{|l|}{$\begin{array}{l}\text { Literature Research Conducted: } \\
\text { - Was literature properly cited? } \\
\text { - Was there a reference list? }\end{array}$} \\
\hline \multicolumn{5}{|l|}{$\begin{array}{l}\text { Research Question/Hypothesis/Objectives: } \\
\text { - Was a research question, hypothesis or objectives presented? } \\
\text { - Was the research question, hypothesi: or objectives well-articulated and easily underatood? }\end{array}$} \\
\hline $\begin{array}{l}\text { Methods, Procedures, and Technical Proficiency: } \\
\text {-Were methods and procedures presented? } \\
\text {-Were methods and procedures used to collect data and information appropriate for the } \\
\text { atudy? } \\
\text { - Did the student provide enough information so you underatood how the investigation wa: } \\
\text { conducted? }\end{array}$ & & & & \\
\hline $\begin{array}{l}\text { Dats and Results } \\
\text { - Were data, resultz, and information presented? } \\
\text { - Were data, results, and information presented clearly uaics sharts, graphs, atatistics, or } \\
\text { other appropriate means. } \\
\text { - Were data, resultz, and information presented in a way that linked to the } \\
\text { question/hypothesi:/objectives of the study? }\end{array}$ & & & & \\
\hline 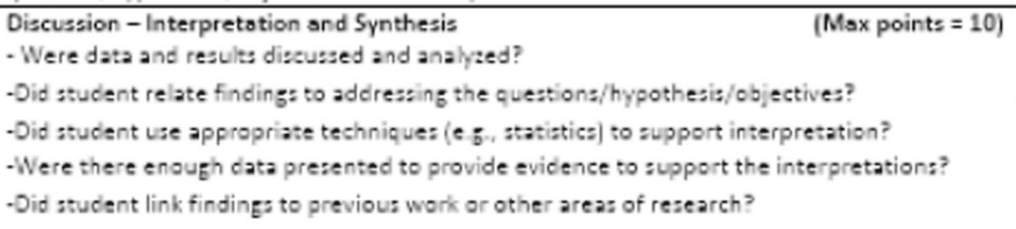 & & & & \\
\hline $\begin{array}{l}\text { Conclusion and Reflection: } \\
\text { - Did student provide conclusions for all project questiona/hypothesis/objectives? } \\
\text {-Were conclusions supported by evidence? } \\
\text {-Were conclusions logical'y presented? } \\
\text { - Did the student reflect on what they would do differently? } \\
\text {-Did the student provide recommendations for future work? }\end{array}$ & & & & \\
\hline $\begin{array}{l}\text { Poster Presentation: } \\
\text { - Did the title engage you in the poster content? } \\
\text { - Was the poster visually appealing? } \\
\text { - Were the grapha, images, tablea readable? } \\
\text { - Was Information organized so you understood it? } \\
\text {-Wa the poster free of apelling and grammatical errors? }\end{array}$ & & & & \\
\hline Total $\quad$ (Moximum Points $=56$ ) & & & & \\
\hline
\end{tabular}

students were given the rubric during the poster development process so they understood the expectations and scoring criteria. Students discuss the rubric and its attributes. They also evaluate posters from previous semesters to see examples of the implementation of poster components. Students can ask clarifying questions before completing their poster task. Prior to final submission, posters were peer-reviewed using the rubric by their class colleagues. 


\section{Evaluation of the rubric measures}

To evaluate the usefulness and practical effectiveness of the refined rubric, a series of comparative and reliability analyses of rubric scores across nine semesters (2014-2018) were conducted using SPSS v25. Determining the reliability of the scoring rubric was especially important because faculty raters varied each semester. These scores also provided information that informed changes in instructional practice to improve student poster performance.

\section{Senior questionnaire}

As part of a reflective process, each senior participant in ENVR 499b completed a "senior questionnaire" that includes two queries about the thesis process. The first query asks the student to rate the overall difficulty of the thesis process using a scale of $1-5,1=$ very easy, $2=$ somewhat easy, $3=$ neutral, $4=$ somewhat difficult, $5=$ very difficult. The second query explores where students experienced challenges during the process. A forced-rank approach required students arrange the following components of the thesis process from least challenging (1) to most challenging (8).

- Finding an adviser

- Topic

- Presentation

- Literature review

- Research question

- Writing

- Research/study

- Time management

\section{Results}

The primary instructor (Gosselin) and three or more faculty, post-docs, or Ph.D. students (a.k.a. faculty raters) assessed posters from 106 senior theses/projects produced from the spring of 2014 to spring 2018 (Table 3). Forty-one raters participated in the poster assessment process that resulted in 438 rubrics. Table 3 reports the sample sizes for each semester.

\section{Assessing the rubric}

ANOVA analysis determined the consistency between faculty rater scores and the control rater (Gosselin). There were no significant differences $F(1,206)=0.435, p=0.132$ in total poster rubric scores between the control rater $(M=$ $45.26, S D=6.05)$ and faculty raters $(M=45.77, S D=$ $5.02)$. There were also no differences between semesters in

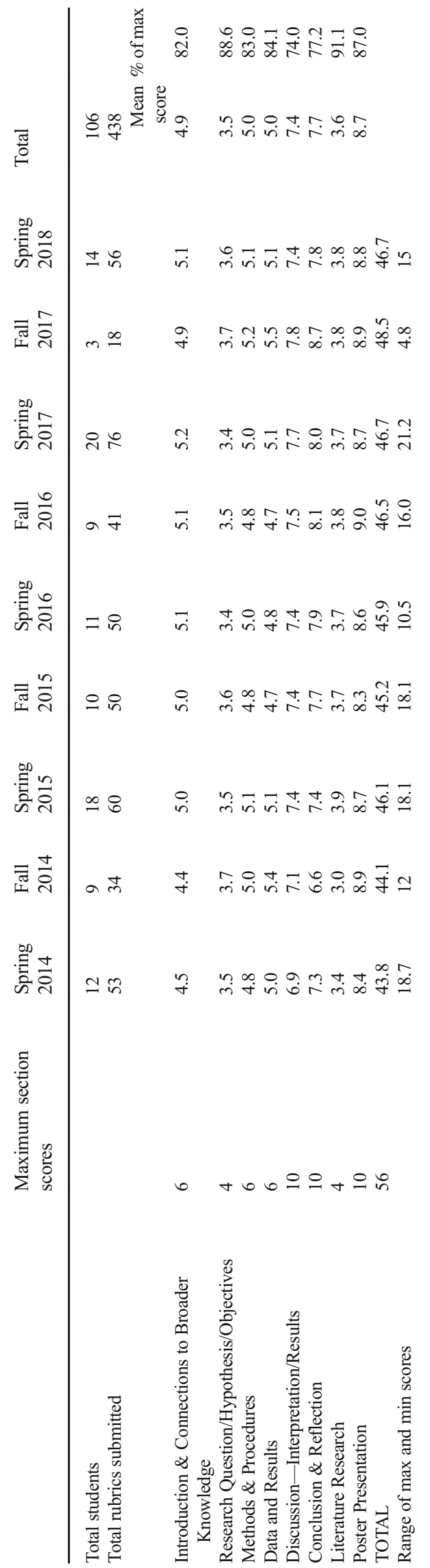


either the control rater scores $F(8,95)=1.36, p=0.224$, or scores of faculty raters $F(8,95)=5.50, p=0.816$. A oneway ANOVA for each item (see Table 4 for items) for each semester indicated that there were significant main effect score for factors by semesters for factors $2 F(8,199)=2.24, p=$ $0.03,6 F(8,199)=2.22, p=0.03$, and $8 F(8,199)=3.63$, $p=0.001$. However, separate Tamhane post hoc tests for factors 2,6 , and 8 indicate no significant differences in factor rating scores between semesters. To determine the interrater reliability of rubric rating scores, Chronbach's alpha analysis of two faculty raters chosen at random for each student poster evaluation indicated that the overall interrater reliability of the rubric across semesters was $\alpha=0.80$. A Chronbach's alpha of 0.70 or above is generally deemed to have acceptable reliability of variance between scores (Taber 2018).

\section{Poster data}

Excluding data from fall 2017 (this semester had 3 students), the average scores by semester ranged from $43.8(\sim 79 \%)$ to a high of $46.7(\sim 83 \%)$ out of the maximum score of 56 . For the eight subsections scored by the rubric, six had average scores of $80 \%$ or above. The lowest average scores occurred in the Discussion - Interpretation/Results (74\%) and Conclusion \& Reflection sections $(77 \%)$. The difference in maximum and minimum total scores for student posters for a given semester ranged from 10.5 to 21 points. The scores do appear to trend upwards from 2014 to 2018 (Fig. 2). However, there is no significant differences between the semesters $F(7,102)=$ $0.513, p=0.823)$.

\section{Senior questionnaire}

Seventy-three $(69 \%)$ of the students correctly completed the forced-ranking part of the questionnaire. These data indicate (Table 5, Fig. 3) that the most challenging aspect of the thesis process was time management (average $=6.1$ ). The second most challenging aspect was writing the thesis (average = 5.3). Coming in a close third was actually conducting the research study (average $=5.2$ ). The easiest part of the process appeared to be finding an adviser (average = 2.6). However, the average difficulty of finding an advisor seems to have increased from 2014 to 2018 (Table 5).

\section{Discussion}

\section{Rubric quality}

One concern that always emerges when a rubric is developed is reliability, that is, to what extent does the rubric yield consistent results. This was of particular concern to the authors because of their interest in respecting people's time and not requiring training to use the rubric. Only minimal instructions on the rubric itself were provided. Although a relatively informal process was used to create and implement the rubric, the inter-rater reliability and the lack of a statistical difference between individual raters and the control rater, supports the reliability of the rubric to provide consistent results. Furthermore, the lack of significant difference between the raters and the control rater serves as a form of normreferencing in that the raters score are compared to how closely the performance matches the score of a standard so to speak, the control rater. Overall the consistency in the application of the rubric is promising and contrasts other studies in which non-expert raters have shown rater leniency, assigning higher scores than justified by the performance of individuals (Tziner et al. 2005). The peer review feedback used in the rubric development along with comments from early evaluators contributed to both the understanding of the rubric and contributed to the face-validity of the questions included in the final rubric.

The analytic rubric in Table 2 allows for the efficient and systematic collection of data from posters by students that

Table 4 ANOVA of main effects of rubric subsections (across semesters)

\begin{tabular}{|c|c|c|c|c|}
\hline & $d f$ & $F$ & $M S$ & $p$ \\
\hline Introduction \& Connections to Broader Knowledge & 8 & 1.514 & 1.821 & .154 \\
\hline Research Question/Hypothesis/Objectives & 8 & 2.241 & 1.016 & $* 0.026$ \\
\hline Methods \& Procedures & 8 & 0.396 & 0.564 & 0.992 \\
\hline Data and Results & 8 & 1.445 & 1.527 & .180 \\
\hline Discussion - Interpretation/Results & 8 & .348 & 1.019 & .946 \\
\hline Conclusion \& Reflection & 8 & 2.222 & 6.221 & $* .027$ \\
\hline Literature Research & 8 & 0.864 & 4.691 & 0.548 \\
\hline Poster Presentation & 8 & 3.634 & 5.883 & $* 0.001$ \\
\hline
\end{tabular}

$N=106$ (total number)

*Significant at $p \geq .05$ 
Fig. 2 Average total poster score

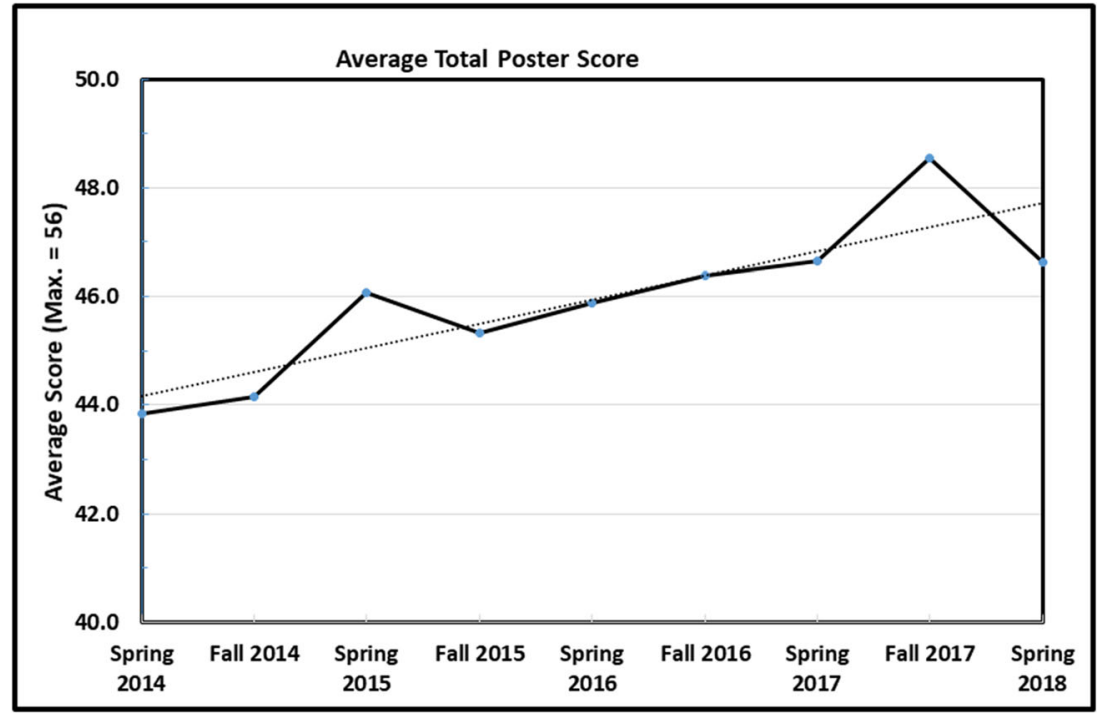

represent a variety of disciplines ranging from the physical, biological, Earth sciences, social science, and the humanities. The posters provide an authentic assessment of the ability of students to apply their knowledge, skills, and learning in the real world task of communication and dissemination of their work. The 0,1 , and 2 scoring approach works because the items are specifically written to assess research process skills and communication through posters and are not discipline specific. This rubric also evaluates diverse poster performance outcomes (see Table 2) which is different from other rubrics focused on visual design aspects (Connelly 2018), student peer review measures (Volz and Saterbak 2009), and information literacy science components (Diller and Phelps 2008). Furthermore, the rubric assessment criteria do not require the rater to have expertise in the subject matter of the poster. To provide flexibility in the assessment process and respect for rater's valuable time, some raters chose to assess posters in person and others conducted a virtual assessment whereby an electronic version of the poster was sent to the rater and the rubric applied. Through personal conversation, raters indicated that the rubric worked well in person and virtually, and that three posters can be easily evaluated in less than an hour. The success of using this rubric assessment for evaluating virtual posters should be seen as promising as there

Table 5 Summary of senior questionnaire data. Scores provided for each item are the average of the useable responses submitted

\begin{tabular}{|c|c|c|c|c|c|c|c|c|c|}
\hline Semester & $\begin{array}{l}\text { Number of useable } \\
\text { process responses } \\
(N=73)\end{array}$ & $\begin{array}{l}\text { Identifying } \\
\text { a topic }\end{array}$ & $\begin{array}{l}\text { Defining the } \\
\text { research } \\
\text { question }\end{array}$ & $\begin{array}{l}\text { Conducting } \\
\text { literature } \\
\text { review }\end{array}$ & $\begin{array}{l}\text { Finding } \\
\text { an } \\
\text { adviser }\end{array}$ & $\begin{array}{l}\text { Conducting the } \\
\text { study/research }\end{array}$ & Writing & $\begin{array}{l}\text { Oral } \\
\text { presentation } \\
\text { of thesis }\end{array}$ & $\begin{array}{l}\text { Time } \\
\text { management }\end{array}$ \\
\hline $\begin{array}{l}\text { Spring } \\
2014\end{array}$ & 4 & 2.5 & 4.0 & 4.3 & 1.8 & 6.8 & 7.3 & 4.0 & 5.5 \\
\hline $\begin{array}{l}\text { Fall } \\
2014\end{array}$ & 4 & 4.5 & 6.3 & 4.8 & 2.0 & 5.8 & 4.8 & 4.3 & 3.8 \\
\hline $\begin{array}{r}\text { Spring } \\
2015\end{array}$ & 9 & 3.2 & 4.3 & 4.2 & 2.6 & 5.1 & 4.8 & 4.4 & 7.3 \\
\hline $\begin{array}{l}\text { Fall } \\
2015\end{array}$ & 7 & 3.6 & 4.7 & 5.0 & 2.4 & 5.4 & 5.1 & 3.0 & 6.7 \\
\hline $\begin{array}{l}\text { Spring } \\
2016\end{array}$ & 8 & 4.3 & 3.8 & 3.6 & 2.1 & 5.4 & 4.4 & 5.6 & 6.9 \\
\hline $\begin{array}{l}\text { Fall } \\
2016\end{array}$ & 8 & 4.9 & 4.3 & 5.0 & 2.5 & 5.9 & 3.8 & 3.1 & 6.6 \\
\hline $\begin{array}{r}\text { Spring } \\
2017\end{array}$ & 16 & 4.2 & 4.6 & 3.8 & 3.4 & 4.6 & 5.4 & 4.4 & 5.6 \\
\hline $\begin{array}{l}\text { Fall } \\
2017\end{array}$ & 2 & 3.0 & 2.0 & 3.5 & 3.5 & 3.5 & 6.5 & 7.5 & 6.5 \\
\hline $\begin{array}{r}\text { Spring } \\
2018\end{array}$ & 15 & 3.1 & 3.7 & 4.7 & 3.5 & 4.5 & 5.3 & 5.0 & 6.2 \\
\hline Average & & 3.7 & 4.2 & 4.3 & 2.6 & 5.2 & 5.3 & 4.6 & 6.1 \\
\hline
\end{tabular}




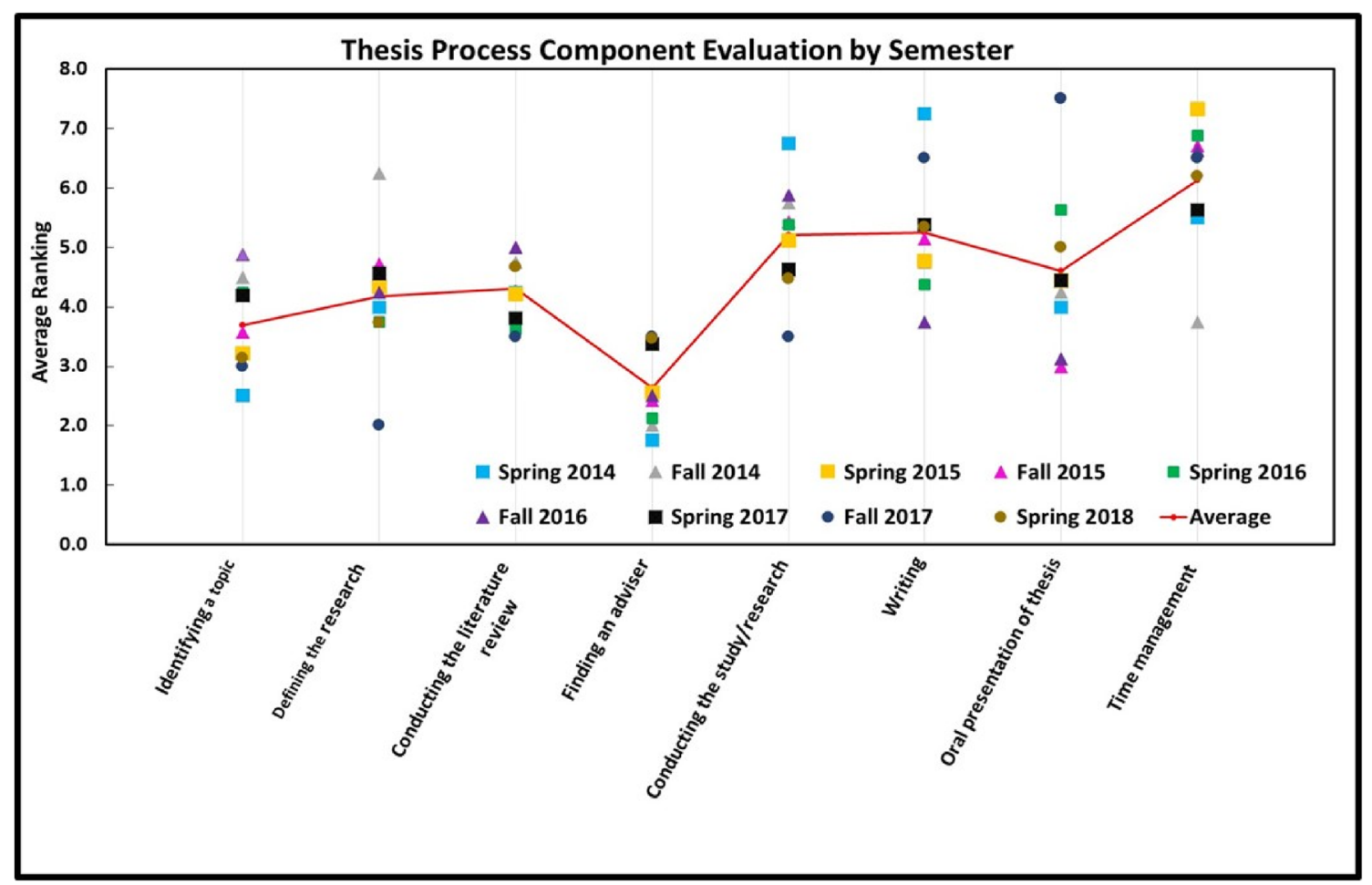

Fig. 3 Thesis process component evaluation by semester

is a growing need for evaluating research posters virtually due to faculty time constraints and in online courses (Menke 2014).

\section{Student performance}

The mean overall scores by semester ranged from 77 to $83 \%$ and had a general upward increase in total scores from the spring 2014 to spring 2018 (Fig. 3). The variations in the range of maximum and minimum average scores (10.5 to 21 points) during a specific semester indicate that although relatively simple approach was used for the development of the rubric, it appears to capture the variation in the quality of the various components of the research process as reflected in the poster. Although explicit student performance levels have not been established by the institution, these data support the basic premise that the assessment of posters provides valuable evidence that students are achieving general proficiency related to the institutional learning outcomes set for this capstone ACE 10 course. These data indicate that students have the ability to organize, plan, and complete a scholarly creative or research product. Students demonstrate that they can use appropriate technical knowledge, field, laboratory, geospatial, and/or social science research methodologies; communicate effectively to a range of audiences through the preparation of oral and visual presentations that are consistent with ACE 10 standards; and collect information, synthesize, interpret, and reflect. Potentially more important to programmatic development is that these data establish a baseline to which future data can be compared.

The average item scores for the six subsections of the rubric indicate mean scores generally above an $80 \%$ proficiency level. A longitudinal examination of the detailed scores for each of rubric items, which are essential factors of the ACE 10 capstone requirements, suggests a general, but not statistically significant increase in scores for six of the eight item scores from 2014 to 2018 (Table 3). Scores for research questions, and data and results essentially have not changed. These items also had the highest starting scores in terms of percentage when the rubric was implemented in spring 2014. The generally high mean scores for research questions reflect the significant emphasis that has been placed on this part of the process because it has been recognized by the instructor as one of the most challenging parts of the ENVR 499 process. The lower scores for subsections Discussion, Interpretation/Results, and Conclusion \& Reflection indicate that student's need more practice with writing in these sections. These sections may be particularly challenging for students as these require the ability to demonstrate higher-level Bloom's Taxonomy skills (as suggested in Kinikin and Hench 2012) such as drawing connections among ideas, interpreting results in context, and appraising and valuing results. Furthermore, the capstone experience is the first time many of these students conduct research and communicate through posters. Howard (2015) linked this inexperience in research posters to the anxiety experienced by some students in presenting posters. The 
difficulty and anxiety around this task is further compounded by difficulty of presenting ideas in a limited space that posters allow MacIntosh-Murray 2007; Akister et al. 2000). Based on student performance, the program plans to have students do smaller research poster creation assignments earlier in their program, to improve their ability to create Discussion, Results, and Conclusion sections and to relieve anxiety during their capstone poster presentations.

One of the important attributes of any program assessment process is that it provides an opportunity for program faculty to reflect on the extent to which their students are learning and to inform future practice. The scores and comments from raters to students on the Introduction and Connections to Broader Knowledge and Literature Research sections in spring 2014 and fall 2014 indicated a general need for improvement in this area. For example, many students had a reference list but did not cite the references in their posters. These items became points of emphasis in the spring 2015 semester. Considerable emphasis has been placed on encouraging students to increase the use of literature to improve the credibility of their work and to help them refine their questioning skills. The upward swing in the scores for these items starting in spring 2015 reflects this emphasis. Another area that needs ongoing attention is the discussion and interpretation of results in the context of their research questions. Scores from the rubric suggest the need for more practice in their course work on writing in the context of their discipline, connecting what they are doing to what work has been done in the past, and citing references in the text to support their ideas.

\section{Senior questionnaire responses and instructional application}

Self-reflection is an important part of experiential learning (Harvey et al. 2016) in that it helps students define their experiences in the context of their understanding. In this case, students reflected on their successes and challenges in conducting research during the final semesters of their program. Furthermore, the senior questionnaire provided students the opportunity to not only reflect on what they have learned, but also to share with program faculty which elements of the research sequence were most challenging. One of the biggest challenges for students is time management as they pursue completion of their projects (Fig. 3). Time management is especially important in capstone projects as the experience spans over many semesters. The experience also requires students to create and present both an oral presentation and poster along with writing a paper. Although many students are familiar with research papers and presentations from other coursework, the ENVR capstone course is not only their first time having to create their own research question, it is often their first opportunity to create a research poster. They underestimate how much time it takes to develop an actionable research question as well as create a poster. Poster development may actually take more time than preparing a similar oral presentation (Brown and Knight 1994; Akister et al. 2000). On a course level, the program has built more structure into the process to help students better manage their time that includes the implementation of more short-term deadlines in both $499 \mathrm{a}$ and $499 \mathrm{~b}$ to help students work through their tendency to procrastinate. As a part of formative assessment for 499a, students have acknowledged their appreciation of the short-term deadlines. The program has also added opportunities to create posters in their first and third year courses.

To address both time management and the challenges related to conducting their studies, students are strongly encouraged to regularly engage and work effectively and often with their thesis mentors (their thesis advisor and readers). Based on 10 years of observation and anecdotal information based on casual personal conversations and those that occurred in conjunction with their final presentations, students who develop strong relationships with their mentors and regularly interact with them are more comfortable with the research design aspects of their projects. This is consistent with previous work that emphasizes the importance of mentors in helping undergraduate students improve research design as well as intellectual support (Behar-Horenstein et al. 2010; Thiry and Laursen 2011). A specific action implemented in spring 2017 to support the development of these relationships was the requirement that students meet with their advisor at a minimum of once a month and document their interactions on a mentor interaction-tracking sheet. These are submitted at the end of each semester. This practice has contributed to the three lowest mean scores for the conducting the study/ research component of the thesis process (Fig. 3).

The second most challenging aspect reported by students is writing up their work. To assist them with this aspect of the process, low-stakes writing activities followed by small group discussions are used to help the student formulate their ideas and conceptual models. These low-stakes writing activities provide the foundation for the two primary components of the thesis proposal-introduction that includes their research questions, literature review, and theoretical frameworks; and methods section. These writing activities along with a significant investment of course time during the first 6 weeks of 499a that focuses on topic selection and research question formulation supported by literature review assignments have resulted in these three aspects of the process generally being viewed as least concerning. The writing component of ENVR 499B becomes more significant as the student begins to bring all the components of the thesis process together. Based on feedback from the students, specific deadlines for the sequential submission of the major parts of the thesis document have implemented along with an in-class peer review.

A somewhat surprising outcome from the senior questionnaire was the relatively low level of challenge attributed to 
finding a thesis advisor. This dispels the initial assumption by program personal that this would be one of the greatest challenges. Furthermore, it dispels an initial misconception by administrators and a recent academic review team that finding advisors is a limiting factor to the growth of the program. However, data from the last three semesters suggests that the challenge to find an advisor may be increasing. This may be because the number of students has increased during that same period. As the program continues to grow, student feedback on this question will continue to be monitored.

\section{Conclusion}

This paper demonstrates an approach for using a research evaluation rubric (a poster rubric), student assignment performance analysis, and student questionnaires to evaluate a capstone research course. This paper demonstrates the use of a relatively simple, yet reliable rubric that can document the student abilities to successfully complete a scholarly creative or research project and meet the requirements of a capstone course using posters. The rubric provides an efficient approach to the assessment of interdisciplinary posters. It documents student success, captures the variability in the quality of the various projects, and provides information for formative assessment that is used for course and program improvement. It also provided a quantitative measurement of where to change approaches to instruction like scaffolded writing tasks.

The rubric effectively addressed the basic assumptions and requirements put forth during its development, especially its relative ease of use without training while at the same time producing consistent results across evaluators. The rubric is not only used as a method of assessment but is also a teaching tool. Its use in providing feedback and as reflection tool enhances the learning experience for students and increases the impact of the senior thesis process on their professional development. This rubric and its implementation to evaluate posters can be modified and used by others to evaluate undergraduate research projects.

Student scores on the poster also allowed us to track performance on the research assignment across semesters. The use of these scores allowed us to evaluate student success in performance of tasks tied into our program goals. It also provided a quantitative measurement of where to change approaches to instruction like scaffolded writing tasks and helped us to emphasize time management and reinforce the need of periodic and frequent engagement between students and research mentors.

The use of a student feedback questionnaire has informed reflective instructional practice, which resulted in increased emphasis on the inclusion of reference citations, use of informal writing activities, and frequency of meetings with faculty mentors. Data from the senior questionnaire in conjunction with the rubric led to emphasis on students having periodic and frequent engagement with their research mentors built into their time management plans.

These changes have resulted in a general, but not statistically significant, increase in total rubric scores in subsequent semesters. These results should be encouraging to other interdisciplinary environmental studies and science programs that seek to efficiently and effectively impact student learning outcomes and evaluate the impact of course changes over several semesters.

\section{References}

Akister J, Bannon A, Mullender-Lock H (2000) Poster presentations in social work education assessment: a case study. Innov Educ Train Int 37(3):229-233

Behar-Horenstein LS, Roberts KW, Dix AC (2010) Mentoring undergraduate researchers: an exploratory study of students' and professors' perceptions. Mentor Tutor Partnership Learn 18(3):269-291

Brown S Knight P (1994) Assessing learners in higher education. Kogan Page, London, pp 161

Connelly LM (2018) Designing effective conference posters. Medsurg Nurs 27(1):64-65

Diller KR, Phelps SF (2008) Learning outcomes, portfolios, and rubrics, oh my! Authentic assessment of an information literacy program. Portal Libr Acad 8(1):75-89. https://doi.org/10.1353/pla.2008.0000

Gosselin D, Cooper S, Bonnstetter RJ, Bonnstetter B (2013) Exploring the assessment of 21 st century professional competencies of undergraduate students in environmental studies through a business academic partnership. J Environ Stud Sci 3:359-368. https://doi. org/10.1007/s13412-013-0140-1.PlusErratum

Harvey M, Coulson D, McMaugh A (2016) Towards a theory of the ecology of reflection: reflective practice for experiential learning in higher education. J Univ Teach Learn Pract 13(2):2

Hawthorne J, Zerr R, Kelsch AV (2018) Assessment of general education: an unexpected (but effective) faculty development opportunity. Chapter 7. New Directions for Teaching and Learning: 155. https://doi.org/10.1002/tl.20304

Howard C (2015) The role of posters as a means of summative assessment. Worcester Journal of Teaching and Learning:10

Kinikin JN, Hench K (2012) Poster presentations as an assessment tool in a third/college level information literacy course: an effective method of measuring student understanding of library research skills. J Inform Lit 6(2)

Kuh GD, Ikenberry SO, Jankowski N, Cain TR, Ewell PT, Hutchings P, Kinzie J (2015) Using evidence of student learning to improve higher education. Jossey-Bass, San Francisco

MacIntosh-Murray A (2007) Poster presentations as a genre in knowledge communication: a case study of forms, norms, and values. Sci Commun 28(3):347-376. https://doi.org/10.1177/ 1075547006298251

Menke JL (2014) Implementation of online poster sessions in online and face-to-face classrooms as a unique assessment tool. J Chem Educ 91(3):414-416

Moskal BM (2003) Recommendations for developing classroom performance assessments and scoring Rubrics. Pract Assess Res Evaluation 8(14). http://PAREonlinenet/getvnasp? $\mathrm{v}=8 \& \mathrm{n}=14$. Accessed 20 Mar 2019 
Palomba C, Banta TW (1999) Assessment essentials: planning, implementing, and improving assessment in higher education. Jossey-Bass, Inc, San Francisco

Skocpol T (2009) Foreword. In Assessment in Political Science. ed. Deardorff MD, Hamann K., and Ishiyama J., xi-xiii. Washington. American Political Science Association

Taber KS (2018) The use of Cronbach's alpha when developing and reporting research instruments in science education. Res Sci Educ 48(6):1273-1296

Thiry H, Laursen SL (2011) The role of student-advisor interactions in apprenticing undergraduate researchers into a scientific community of practice. J Sci Educ Technol 20:771-784. https://doi.org/10.1007/ s10956-010-9271-2
Todd M, Bannister P, Clegg Sc (2004) Independent inquiry and the undergraduate dissertation: perceptions and experiences of final-year social science students. Assessment \& Evaluation in Higher Education 29(3):335-355

Tziner A, Murphy KR, Cleveland JN (2005) Contextual and rater factors affecting rating behavior. Group Organ Manag 30:89-98

Volz T, Saterbak A (2009) Students' strengths and weaknesses in evaluating technical arguments as revealed through implementing Calibrated Peer Review ${ }^{\mathrm{TM}}$ in a bioengineering laboratory. Across Discip 6(1)

Weaver KF, Morales V, Nelson M, Weaver PF, Toledo A, Godde K (2016) The benefits of peer review and a multisemester capstone writing series on inquiry and analysis skills in an undergraduate thesis. CBE Life Sci Educ 15(4):ar51 